\section{Don C. Wiley}

\author{
Ian A. Wilson
}

The accidental death of Professor Don C. Wiley, Harvard University, on November 16,2001 , has deeply saddened the scientific community worldwide. The passing of Dr. Wiley is especially tragic for his wife, Katrin Valgeirsdottir and their two children, as well as Don's two children from a previous marriage.

Don was born in Akron, Ohio on October 21, 1944. He went to Tufts University as an undergraduate and took his Bachelor of Science in Physics and Chemistry in 1966. He then became a graduate student in Biophysics at Harvard University with Prof. ("Colonel") William Lipscomb. Don pioneered what was to become a long-term Lipscomb project on the structure and function of aspartate transcarbamoylase. He achieved a $5.5 \AA$ structure of this very complex enzyme, which was a significant achievement in those early days of crystallography, barely a decade after the first protein structure, myoglobin, was determined by Sir John Kendrew and others. However, this structure was far more complicated than that of myoglobin, with six regulatory and six catalytic subunits and was to become a poster child for allosteric regulation, and a scientific goldmine and training vehicle for many graduate students and postdoctoral fellows in Lipscomb's lab for the next thirty years.

Don skipped the usual postdoctoral stage and became an Assistant Professor in the Department of Biochemistry and Molecular Biophysics at Harvard. $\mathrm{He}$ moved downstairs onto the first floor of the Wolcott Gibbs Memorial Laboratory, and set up what was to evolve into a productive, happy, and symbiotic relationship, involving shared lab space and resources, with Steve Harrison for the next 30 years. During these first five faculty years, Don searched for a suitable project for his laboratory and was drawn to the report of crystals of influenza virus hemagglutinin (HA) glycoprotein that had been reported by Brand and Skehel in 1972. His friendship and continuous collaboration with Sir John Skehel was to become the foundation from which his lab was built. Don went on sabbatical leave to Mill Hill, London and the Medical Research Council (MRC) Cambridge in 1976 on a European

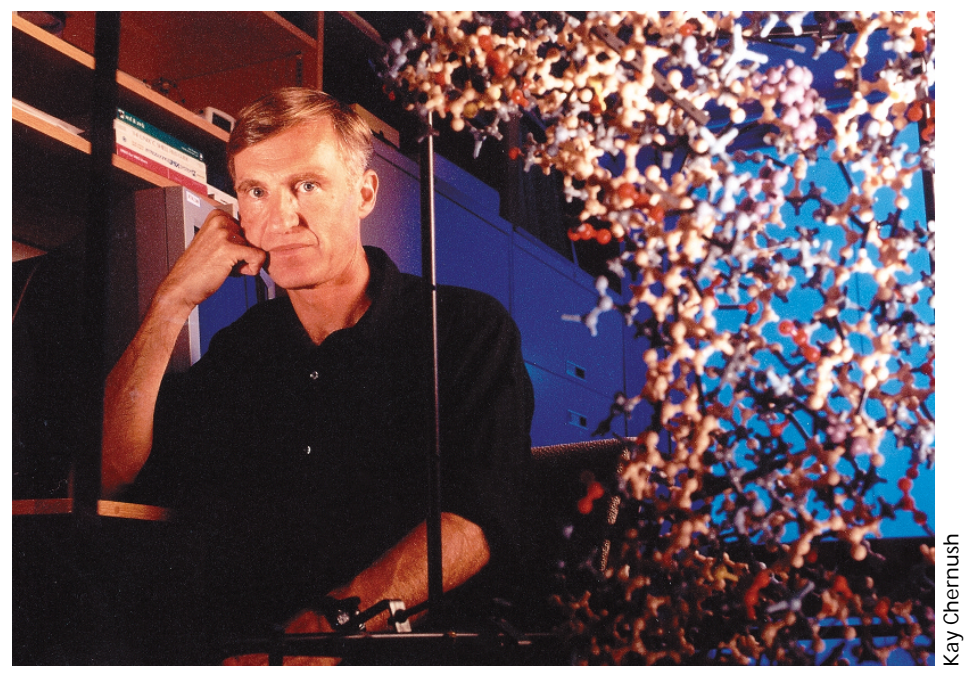

1944-2001

Molecular Biology Fellowship to pursue the crystallization and diffraction studies of the A/Hong Kong 1968 influenza virus hemagglutinin. John had managed to cleave this major influenza cell surface antigen from the viral envelope using bromelain. What seemed incredible at the time was that this heavily glycosylated $220 \mathrm{kDa}$ trimer containing 25\% carbohydrate (7 different sugar sites) would crystallize, let alone diffract.

It was at this stage that I became enormously interested in this project. Through a chance visit to Oxford, Christoph Kratky, from Martin Karplus' laboratory (Harvard) at the time, told me about Don's work on the hemagglutinin. On Christoph's return to Harvard, Don sent me a copy of his recently submitted grant on the hemagglutinin. I was stunned and nervously went to my boss at the time, David Phillips, to seek his approval to join Don's lab, rather than remain in Oxford.

With high expectations, I joined Don's lab as his first postdoctoral fellow in 1977, only to discover there hardly was a lab it consisted of Judy White, Don's first graduate student; Ed Gordon, a part-time technician; and Frank Escobar, a Harvard undergraduate. Coming from what now seemed like a giant palace of crystallography in the Molecular Biophysics lab in Oxford, this came as a tremendous shock. Steve Harrison had a few, but not many, more people, and when some members of
Lipscomb's lab joined us our numbers at daily afternoon tea could swell to around 10-12.

The next five years were to be as exciting as one could ever imagine in a scientific venture. Crystals of the native HA were in hand. I remember that we received monthly shipments of the HA protein from John in hand-blown glass vials lovingly cradled in fluffy white cotton wool. The HA had been extracted from influenza virus grown in dozens of cartons of eggs. The next two years were spent collecting countless oscillation photographs on an Elliott X-ray GX-6 machine of both native and heavy atom derivatives of HA. Don's lab was not well funded by Harvard's or any other standards; so we were destined to compute, using endless boxes of cards, over the telephone lines to Columbia University at night in order to avoid the excessive charges for daytime use that others could afford. For what seemed like an eternity, Don and I computed away every night from 8:00 p.m.-6:00 a.m. until we found a suitable heavy atom derivative. Only one was found, which necessitated contemplating averaging and solvent flattening - that concept had only been applied so far to viruses due to their extensive non-crystallographic symmetry. Don adapted the Bricogne Program that Steve Harrison had used for tomato bushy stunt virus (TBSV), provoking a great 
Fig.1 Schematic drawing of the influenza virus hemagglutinin showing the amino acid mutations that accumulated in viral strains circulating in the world from 1968 to 1977, as well as some laboratory-selected antigen variants. Four distinct regions of HA (filled circle, site A; filled square, site B; filled triangle site C; filled diamond, site D (subunit interface); open diamond, surface; open circle, neutral) contained most HA of the mutations that allow the virus to escape neutralizing by antibodies, and, hence, lead to new epidemic strains. As new data emerged, Don would place red stickers onto the model to record the antigenic variation. These data were invaluable to the Centers for Disease Control (CDC) in deciding when a change was needed in the flu vaccine from year to year (this diagram was modified from its first publication by Wiley, D.C. et al. Nature $\mathbf{2 8 9}$, 373-378; 1981).

deal of skepticism even from Bricogne who questioned whether three-fold averaging of data phased on a single derivative with no anomalous information could work. It did!

Don computed the first maps at $3 \AA$ resolution, in which it was hard to discern even the outline of the protein. However, the extremely high solvent content of the crystals (82\%) helped enormously, as well as the fidelity of the three-fold axis painstakingly gleaned from determining the positions of two independent heavy atom sites from the Patterson maps. I was assigned to trace the protein envelope by hand and then to transfer that information into the computer to allow further rounds of averaging and solvent flattening. Then, cycle by cycle, the map improved culminating with a $75 \%$ phase difference from beginning to end - one could now visualize the outline of the long trimer of the HA stacked like Lincoln logs head to tail around a fourfold screw axis.

The structure was one of the first to be built on the computer, rather than in a Richard's box, using the BILDER program of Bob Diamond, as modified by Bob Ladner at Harvard. The structure was simply amazing with its globular head and long helical coiled-coil stem. The beauty was that there was a plethora of data on the amino acid changes that occurred in the HA in going from the pandemic strain of 1968 to the subsequent influenza epidemics. However, the difficulty was in actually visualizing the structure, as there were no graphics programs at the time so Hidde Ploegh, in Jack Strominger's lab, was co-opted to utilize his artistic talents to come up with a schematic of the structure that could convey its biological message to the community. Many versions and attempts later, the final, now classic, view of the HA was produced (Fig. 1). With great excitement, Don started to map the antigenic variation of the influenza virus from 1968 to 1977 onto the HA structure by sticking different shaped red dots onto the schematic drawing (Fig. 1). The results were astounding as the mutations mapped into four dis- crete areas on the HA structure - it appeared that for a new viral epidemic strain to emerge, mutations were required in four regions on the surface. It was also immediately apparent that carbohydrate could mask the surface and help render the virus invisible to the immune system, whereas the few highly exposed regions accommodated most of the amino acid variation and acted as a decoy to avert the immune response away from the conserved receptor binding site.

The impact of this structure on the was profound - in fact, long before Don even got to talk about the structure at any meetings, rumors were circulating. I remember Don's first presentation at a Gordon Conference in New Hampshire in 1981; he was so excited that he would stop anyone in his path, pull out the structure, and explain its glorious beauty and the insights it revealed about antigenic variation in influenza virus. It was an experience that happens perhaps only once, if ever, in one's lifetime - a crystal structure that had life and talked. But Don wasn't finished yet; he had only just begun.

Two years after I joined the lab, Pamela Bjorkman came to Don's lab as a graduate student. She was impressed by discussions with Jim Kaufman in Jack Strominger's lab on how they could produce large quantities of the major histocompatibility (MHC) complex class I molecule, HLA-A2. This project would be a perfect complement to the HA project, as one could now investigate the structurwork by Zinkernagel and Doherty, who were awarded the Nobel Prize in 1996, it was shown that dual recognition of both antigen and MHC was needed on antigen presenting cells in order to get $\mathrm{T}$ cell killing. Thus, it was surmised that the MHC structure could be docked alongside the HA structure to understand the recognition complex that $\mathrm{T}$ cells presumably would have to see on the cell surface.

The difficulty in obtaining suitable heavy atoms on these wafer-thin crystals took several years and multiple trips to synchrotron radiation sources in the U.S. virology and immunology communities al basis of MHC restriction. Thanks to

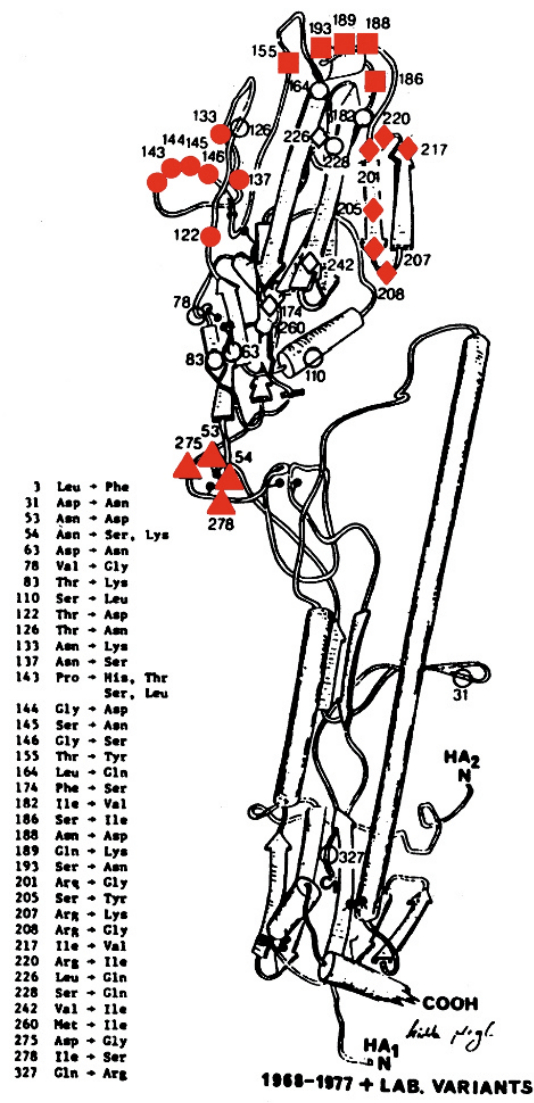

and abroad, especially to CHESS at Cornell and to Hamburg in Germany. As the HA project matured, Don diverted more of his time to thinking about how the cellular immune system functions, and the role that MHC played in the response. In 1987, the HLA-A2 structure was finally unmasked and another historic milestone was achieved. The HLA structure revealed a completely new fold, now known as the MHC fold, with an eight-stranded $\beta$-platform on which two long $\alpha$-helical segments sat and traversed the sheet. Between the $\alpha$-helices and the $\beta$-sheet floor was a long, narrow groove in which extra density was seen that could not be accounted for by atoms of the MHC (Fig. 2). Voila! The density must be the elusive antigen! Or, more accurately, one or a mixture of the short peptides that were later shown to be derived from digestion of the intact protein antigens by the proteasome.

The MHC is the most polymorphic region in the human genome - the polymorphic residues of the class I MHC mapped beautifully onto the walls and floor of the groove exactly where the peptide contacted the MHC. At last, one could visualize how the MHC was able to present peptides to the $\mathrm{T}$ cell receptor. The polymorphisms themselves would 


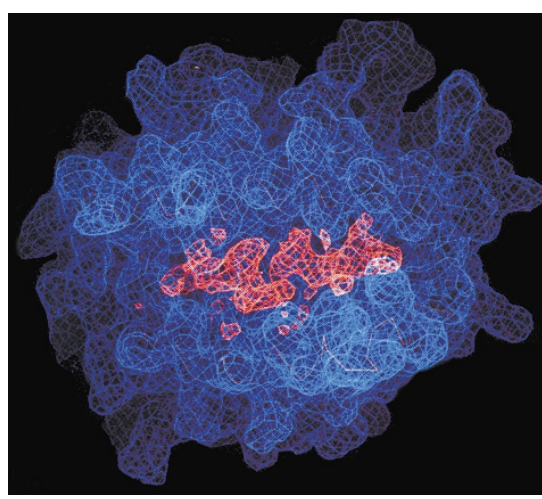

alter the peptide repertoire presented by individual MHC molecules and account for how the population as a whole could be protected from viral and other microbial pathogens. Another structure that talked — and loudly! It would take another five years to untangle the details of the peptide interaction due to the difficulty of making single peptide MHC complexes. But what was remarkable was that this HLA-A2 binding groove already contained a mixture of peptides that remained throughout the protein purification from intact cells. The first MHC class II structure, DR1, followed in 1993.

Many, many more important findings were to emerge from Don's lab. On the HA front, structural identification of the sialic acid receptor binding site, the $\mathrm{pH}-$ triggered fusion active form of the virus, the intact $\mathrm{HA}_{0}$ precursor molecule, and various other HA's from different strains and subtypes. The HA was to become the model for how the enveloped viruses fuse their membranes with the host cell. Don followed up that work with the structures of fusion domains of gp41 for

Fig. 2 A van der Waals surface representation (blue) of the first structure of an MHC class I molecule HLA-A2. Surprisingly, extra electron density (red) was found in a long, narrow groove between the $\alpha$-helices of the MHC that identified the location of a bound peptide ligand. This density is likely to represent a mixture of peptides that is retained throughout purification of the protein from cells. This figure first appeared in Nature (Bjorkman, et al. 329, 506-512; 1987).

HIV-1 and Ebola virus. The whole viral membrane fusion story was extremely compelling and I was fascinated to hear Don talk about how much it had progressed last year. He always liked to talk about the $\mathrm{HA}$ - it was a passion that lasted from 1975.

The next big structure represented the final piece of the puzzle in the cellular recognition story - the $\mathrm{T}$ cell receptor (TCR). In 1996, David Garboczi and Partho Ghosh completed the structure of the human $\mathrm{T}$ cell receptor, $\mathrm{A} 6$, bound to HLA-A2. This structure revealed how the TCR could recognize both peptide and MHC, and how the TCR adopted a particular diagonal orientation on the $\mathrm{pMHC}$ This stunning achievement was augmented by the corresponding finding from our own lab that mouse TCRs adopt the same diagonal orientation on their MHC class I. These studies began to reveal the structural basis for alloreactivity, positive and negative selection, tolerance, and graft rejection.

It is hard to capture the vastness of the contributions that Don made to virology, immunology, structural biology molecular biology, cell biology, and biochemistry. Any one of his many achievements would have made most investigators happy for their entire academic lifetime. His legacy is monumental. It is the epitome of how structural work can facilitate a deep understanding of complex biological processes. For this work, Don was awarded many of the world's top scientific prizes and awards, including the prestigious Gairdner Foundation Award, 1994; the Lasker Award, 1995; and the Japan Prize, 1999. He became a Howard Hughes Medical Institute investigator in 1987, and was elected to the National Academy of Sciences in 1991. He was the John L. Loeb Professor of Biochemistry and Biophysics at Harvard University.

Don was a captivating speaker who always had profound thoughts. His reasoning was painstakingly thorough. $\mathrm{He}$ also didn't suffer whom he considered to be fools lightly and was always quick to give his view of the error of their ways in his own inimitable way. Don was not simply a structural biologist - he was the consummate scientist that most aspire to but never attain. His vision of what were quality problems to solve was key to the success of his laboratory. It was a storied career that lasted three glorious decades. In our sorrow over this terrible tragedy, we celebrate and pay tribute to the tremendous career that brought so many insights into really important scientific problems.

Ian A. Wilson is in the Department of Molecular Biology \& the Skaggs Institute for Chemical Biology, the Scripps Research Institute, 10550 North Torrey Pines Road, La Jolla, California 92037, USA. email: wilson@scripps.edu 